\section{MAKE ROUTINE PROCEDURES EASIER}

Qudent have introduced a new air prophy unit to their range. Air polishing is a highly effective way to return teeth to brilliant whiteness and the Easy Flow is perfect for removing stains and polishing teeth.

The Easy Flow can be used to clean teeth, remove stains and polish teeth after de-bonding, making these routine procedures easier and more efficient. It is compact, easy to clean and sterilise after use as well as being compatible with various types of handpiece adaptor.

The Easy Flow is available with Kavo, Bien Air, NSK or WEH adaptors for a quick and easy connection. Alternative

\section{INTEGRATION BETWEEN CAD/CAM AND X-RAY DATA}

Sirona Dental Systems have announced the arrival of their latest news in Galileos CBCT software. This exciting

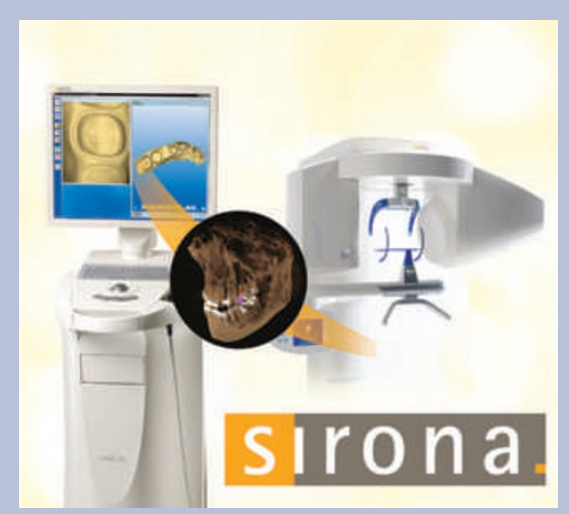

development in CBCT technology allows the integration between Sirona's CEREC CAD/CAM software and Sirona's Galileos CBCT X-ray data.

Surgical and prosthetic planning can now be performed precisely and safely in a single visit. Until now CBCT was limited to hard tissue images and lacked the ability to capture periodontal tissue data. For the very first time in CBCT imaging, the periodontal tissues can now be evaluated for location and thickness in $3 \mathrm{D}$ as it relates to the hard tissue thanks to CEREC surface data. Reader response number 60

\title{
FREE CPD AT DENTAL SHOWCASE 2010
}

There are a range of ways in which you can obtain CPD for free at this year's BDTA Dental Showcase. Whether you prefer to learn hands-on or by listening, discussing, reading or a combination of all three, there is something to suit you.

Hour long complimentary seminars covering the core subjects recommended by the GDC will be hosted over the three day event. Showcase visitors can attend a maximum of one seminar each day and will receive up to one hour of verifiable CPD entry. The lecture theatre has been designed to cope with the expected demand so there is no need for advance booking.

Also available will be feature lectures taking place before the exhibition opens each day. These will provide useful insights into the latest developments in dentistry.

In addition, BDTA Dental Showcase provides the perfect opportunity to learn about the latest materials, equipment, products, services and technologies by walking around the exhibition, enabling the core CPD subject to be comprehensively covered to improve knowledge and understanding of new techniques. And by answering questions relating to the dental and business articles, members of the dental team will be able to gain verifiable CPD hours for reading the Show Guide which accompanies BDTA Dental Showcase. There will be a total of five articles featuring in a special CPD section of the Guide covering clinical and business topics.

Finally, new for 2010 is the Knowledge Hunt, which gives you the opportunity to record key information as you walk around the exhibition. Questions will be included in the Show Guide which you will be able to answer as you visit stands in the hall.

BDTA Dental Showcase 2010 takes place 14-16 October 2010 at ExCeL London. To register in advance for your complimentary ticket visit www.dentalshowcase.com/visit.

Reader response number 61

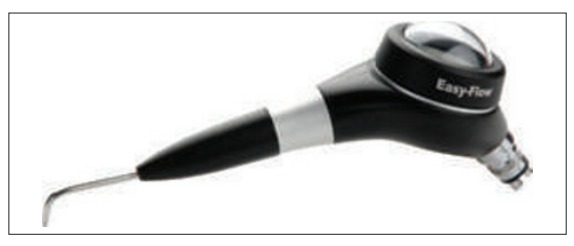

prophy powders are available on request and the unit is competitively priced.

Reader response number 59

\section{POTENT ANTIMICROBIAL FORMULA}

Controlling the symptoms of gingivitis is important to dental patients and the alleviation of the irritation of inflamed, sensitive gums can be achieved with effective oral care. A daily oral hygiene regime is most effective when combined with an antibacterial agent in order to control gingivitis and prevent further deterioration in the condition of the gums.

Chlorhexidine Gluconate contains a potent antimicrobial formula that directly combats the formation of plaque and is well recognised for its efficacy in the treatment of gingivitis.

Chlorhexidine Gluconate reduces infection and is additionally effective in treating oral candida, and since its active ingredient is designed to reduce oral bacteria, it can help improve bad breath.

Formulated as a powerful yet gentle mouthwash, Chlorhexidine Gluconate is available from Blackwell Supplies in a choice of two flavours: Original and Peppermint.

A cost-effective and high quality product, Chlorhexidine Gluconate can be recommended to patients as an essential tool in the fight against gingivitis.

\section{Reader response number 62}

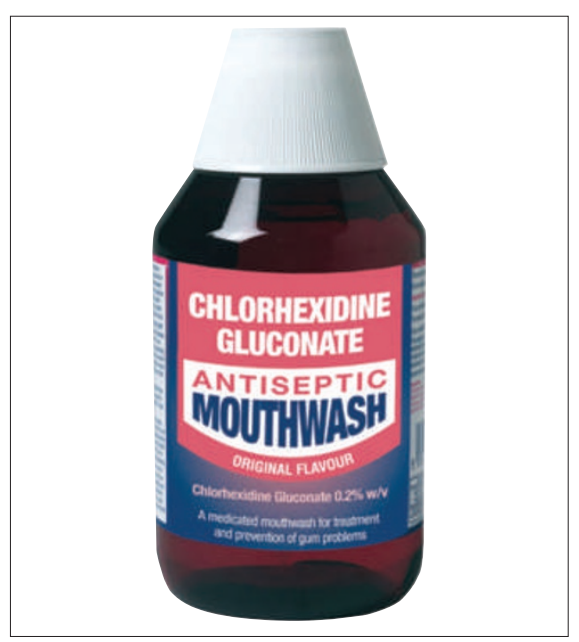

